\title{
Challenges to detect glaucomatous visual field loss with pupil perimetry
}

This article was published in the following Dove Press journal:

Clinical Ophthalmology

\author{
Ken Asakawa' \\ Nobuyuki Shoji ${ }^{2}$ \\ 'Department of Orthoptics and Visual \\ Science, School of Allied Health Sciences, \\ Kitasato University, Kanagawa, Japan; \\ ${ }^{2}$ Department of Ophthalmology, School \\ of Medicine, Kitasato University, \\ Kanagawa, Japan
}

\begin{abstract}
We evaluated the pattern deviation of pupil fields to differentiate a glaucomatous damage using the head-mounted perimeter "imo". Thirty-four eyes of 26 glaucoma patients (mean age, 55.1 years) were examined. The pattern deviation ( 85 th percentile) of pupil fields was calculated from the difference between age-matched normal and abnormal percentage pupil constriction. Consequently, glaucomatous damages were remarkably distinguished from the normal pupil fields using the pattern deviation of the imo.
\end{abstract}

Keywords: pupil field, glaucoma, pattern deviation

\section{Introduction}

Most of the current visual field tests are based on subjective rather than objective responses. Therefore, the accuracy and reliability of these tests often depend on the degree of the patients' cooperation. Pupil perimetry is becoming more common as an objective method to evaluate visual fields using pupillary response. ${ }^{1-3}$ However, the usefulness remains unclear due to the large data variability among pupil samples, anatomical differences of cells and pathways of visual field and pupillary response.

The head-mounted perimeter "imo" (CREWT Medical Systems, Tokyo, Japan) can simultaneously record the pupillary responses during target presentation. ${ }^{4-6}$ In our prior study, ${ }^{4}$ a quite flat age dependence was obtained in the normative pupillary response by age, and the response was consistent with the distribution densities and receptive fields of cells as it was with visual field sensitivity. Pupil fields of the imo generally correspond to the visual fields with the Humphrey Field Analyzer (HFA) (Carl Zeiss Meditec, Dublin, CA, USA) in hemianopsia and glaucoma patients. ${ }^{5,6}$ However, some glaucoma patients have a poor correlation. ${ }^{6}$ The aim of the study is to evaluate the pattern deviation of pupil fields to differentiate a glaucomatous damage.

\section{Materials and methods}

The definite criteria used for defining glaucoma and the details about the agematched control subjects considered for the calculations were provided by Totsuka et $\mathrm{al}^{6}$ and Asakawa et $\mathrm{al}^{4}$, respectively. The inclusion criteria require a pupil size of at least $3 \mathrm{~mm}$ without dilation to obtain good-pupillary response. The visual fields were measured with the HFA 24-2 and 10-2 programs. Subjects with more than $15 \%$ of false-positive and $33 \%$ of false-negative responses were excluded. Fixation loss responses were also excluded.
Department of Orthoptics and Visua Science, Kitasato University, School of Allied Health Sciences, I-I5-I Kitasato, Sagamihara, Minami-ku, Kanagawa 252-0373, Japan

Tel +8I 427789667

Fax +8I 427789684

Email asaken@kitasato-u.ac.jp 
Thirty-four eyes of 26 glaucoma patients, ranging in age from 38 to 69 years (mean age, 55.1 years) were examined. Glaucomatous eyes were classified into 3 stages using the Hodapp-Anderson-Parrish grading scale (12 early, 13 moderate, and 9 severe eyes). ${ }^{7}$ There were cases of normal-tension glaucoma in 13 eyes of 10 patients and of primary open-angle glaucoma in 21 eyes of 16 patients. The tenets of the Declaration of Helsinki for research involving human subjects were followed, and written informed consent was obtained. The protocol was approved by the Institutional Ethics Committee of Kitasato University (No. B17-031).

The outline for the pupil field testing with imo has previously been described in detail. ${ }^{4-6}$ The measurement conditions were set to a Goldmann size V target, a target luminance of 10,000 apostilbs (asb), equivalent to 0 decibels on the HFA scale and a background luminance of 31.4 asb. Targets were presented for 1 second at each of the 36 test points. Percentage pupil constriction was then automatically calculated with the following equation: (initial pupil size before light stimulus - minimal pupil size after light stimulus)/(initial pupil size before light stimulus) $\times 100(\%)$.

Based on our previous study, ${ }^{8}$ in the 36 test points, the sensitivity of the seventh highest point when compared with the normal value was used as the standard degree of sensitivity for the entire visual field. The pattern deviation (85th percentile) of the pupil field was calculated as a value representing the difference between age-matched normal and abnormal percentage pupil constriction. Probability plots were expressed as: $25 \%$ black $(P<10 \%), \quad \mathbf{\square 0} \%$ black $(P<5 \%), \quad-75 \%$ black $(P<2 \%), \quad-100 \%$ black $(P<1 \%)$. The detection rate of abnormal points (\%) (less than $P<10 \%$ of imo/less than $P<5 \%$ of HFA) was then evaluated in correspondence to the HFA $24-2$ and 10-2 test points.

The detection rate of abnormal points of each glaucoma severity was compared using one-way analysis of variance, with the Scheffe test for post hoc comparisons. A $p$-value of $<0.05$ was considered statistically significant.

\section{Results}

Typical results are shown in Figure 1. Glaucomatous damage, even localized defects were distinguished from the normal test points by use of a pattern deviation. There were significant differences between the glaucoma severity in the detection rate of abnormal points (temporal area: early vs moderate $P=0.8922$, early vs severe $P=0.9999$; nasal area: early vs moderate $P=0.0941$, early vs severe $P=0.0007$ ) but not with the glaucoma types (Table 1).

\section{Discussion}

In previous studies, Yoshitomi et $\mathrm{al}^{9}$ and Schmid et al ${ }^{10}$ reported that early glaucoma with a localized visual field loss has a poor correspondence between the subjective standard automated perimetry and objective pupil perimetry. One of the positive aspects is that pupil perimetry would more accurately reflect retinal nerve fiber layer loss in early glaucoma. ${ }^{11}$ However, Tatsumi et $\mathrm{al}^{12}$ reported that the log-scaled relative afferent pupillary defect (RAPD) was associated with the structural loss of retinal nerve fibers and/or ganglion cells. Adhikari et al ${ }^{13}$ also examined the amplitude of pupil constriction in the glaucoma severity, and they reported that the moderate to severe glaucoma patients exhibited lower amplitudes of pupil constriction. In this study, we could not be performed conventional pupillary evaluation (e.g., swinging flashlight test and infrared pupillography). To overcome this limitation, we will evaluate the presence and grades of a RAPD among the glaucoma patient subsets in subsequent studies.

On the other hand, the pattern deviation has been widely accepted as an analytic method for identifying abnormal test points of HFA. The probability plots emphasize localized loss after adjustment for age. ${ }^{14}$ The pattern deviation of HFA as it calculates general height from the total deviation by considering multiple factors including refractive error, pupil diameter and diffuse medial opacity. Our approach may not be comparable with the pattern deviation of HFA. However, this is the first report the possibility of using a pattern deviation obtained from the pupil field testing with imo as a diagnostic strategy for detecting glaucomatous damage. Consequently, our results demonstrated that the difference between an age-matched normal and abnormal pupil value indicated a localized glaucomatous damage in pupil perimetry of the imo.

\section{Acknowledgment}

The authors thank Robert E. Brandt of MedEd Japan for editing the manuscript. This study was supported by Kitasato University Research Grant for Young Researchers (2019) and Kitasato University School of Allied Health Sciences Grant in-Aid for Research Project (No. 2019-1031). CREWT Medical Systems (No. 2812232) provided the head-mounted perimeter "imo" without fee for 2 years. 
A

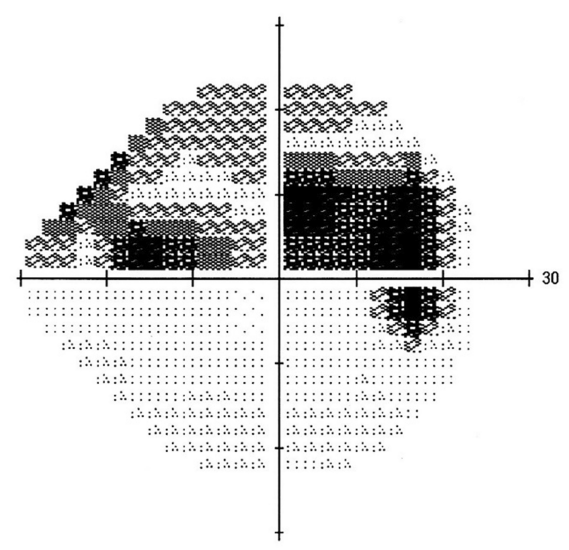

C

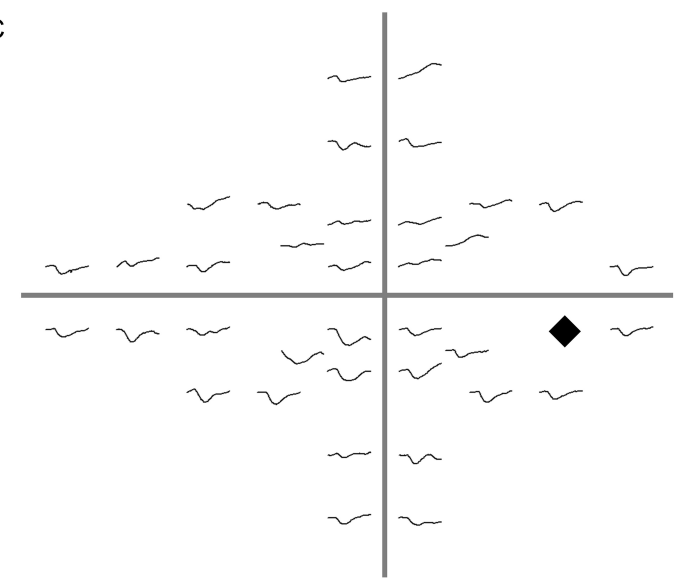

$\mathrm{E}$

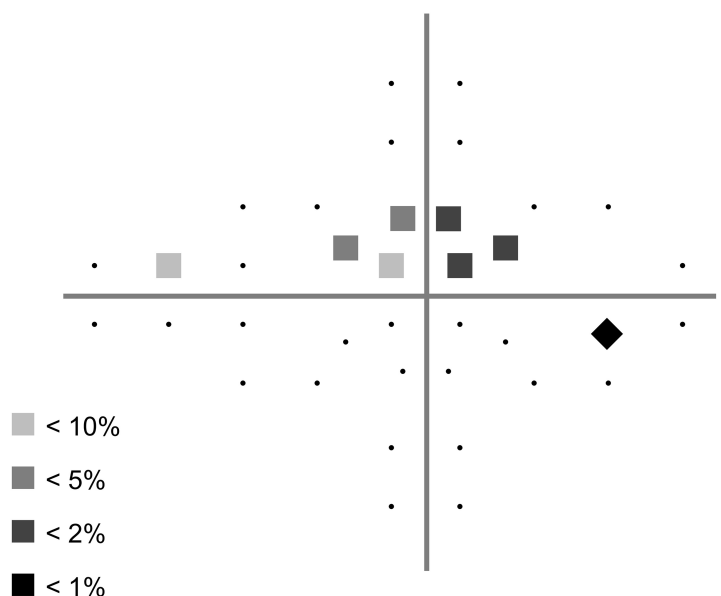

B

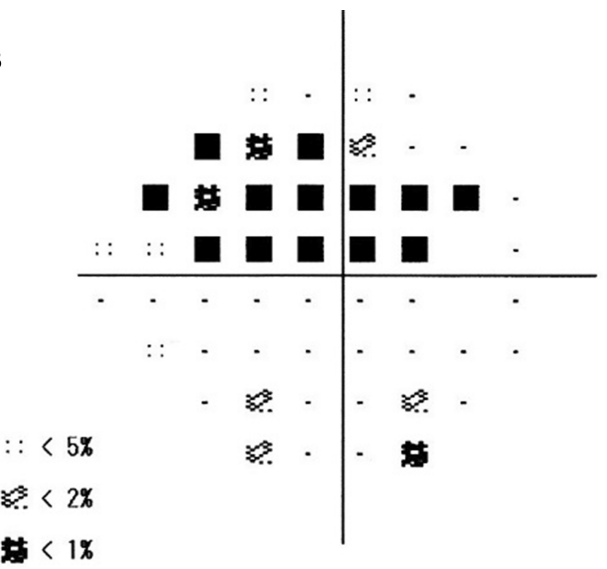

$<0.5 \%$
$\mathrm{F}$

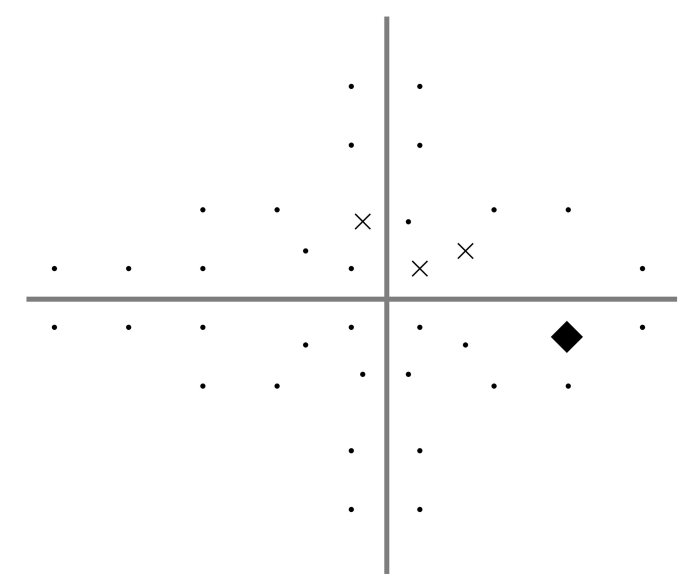

Figure I Measured results of glaucoma patient (67-years male, primary open-angle glaucoma, Mean deviation $-8.90 \mathrm{~dB}$, Pattern standard deviation $8.83 \mathrm{~dB}$, Visual field index 74\%). (A) Gray scale of Humphrey Field Analyzer (HFA), (B) Pattern deviation of HFA, (C) Pupil waveforms, (D) Percentage pupil constriction (\%), (E) Pattern deviation ( $\mathbf{- 2 5 \%}$ black; $P<10 \%, \mathbf{- 5 0 \%}$ black; $P<5 \%, \mathbf{- 7 5 \%}$ black; $P<2 \%, \mathbf{- 1 0 0 \%}$ black; $P<1 \%$ ), (F) Subjective response (It can be simultaneously recorded if the patient pushes a button). 
Table I Detection rate of abnormal points in each test point

\begin{tabular}{|c|c|c|c|c|c|c|}
\hline & \multicolumn{2}{|l|}{ Test points } & \multirow{2}{*}{$\begin{array}{l}\text { Superior } \\
\text { /Inferior }\end{array}$} & Early & Moderate & Severe \\
\hline & Horizontal & Vertical & & \multicolumn{3}{|c|}{ Detection rate of abnormal points (imo/HFA) } \\
\hline \multirow[t]{17}{*}{ Temporal } & \multirow[t]{2}{*}{$1^{\circ}$} & \multirow[t]{2}{*}{$7^{\circ}$} & S & $43(3 / 7)$ & $57(4 / 7)$ & $63(5 / 8)$ \\
\hline & & & 1 & $0(0 / 1)$ & $83(5 / 6)$ & $17(1 / 6)$ \\
\hline & \multirow[t]{6}{*}{$3^{\circ}$} & \multirow[t]{2}{*}{$3^{\circ}$} & S & $0(0 / 3)$ & $57(4 / 7)$ & $43(3 / 7)$ \\
\hline & & & 1 & $0(0 / 1)$ & $0(0 / 2)$ & $33(1 / 3)$ \\
\hline & & \multirow[t]{2}{*}{$15^{\circ}$} & S & $20(1 / 5)$ & $50(4 / 8)$ & $25(2 / 8)$ \\
\hline & & & I & $0(0 / 3)$ & $0(0 / 6)$ & $0(0 / 5)$ \\
\hline & & \multirow[t]{2}{*}{$21^{\circ}$} & S & $0(0 / 2)$ & $29(2 / 7)$ & $17(1 / 6)$ \\
\hline & & & I & $0(0 / 2)$ & $0(0 / 5)$ & $0(0 / 3)$ \\
\hline & \multirow[t]{2}{*}{$7^{\circ}$} & \multirow[t]{2}{*}{$5^{\circ}$} & S & $86(6 / 7)$ & $50(4 / 8)$ & $29(2 / 7)$ \\
\hline & & & I & $0(0 / 0)$ & $40(2 / 5)$ & $0(0 / 4)$ \\
\hline & \multirow[t]{2}{*}{$9^{\circ}$} & \multirow[t]{4}{*}{$9^{\circ}$} & $S$ & $0(0 / 2)$ & $22(2 / 9)$ & $25(2 / 8)$ \\
\hline & & & 1 & $0(0 / 2)$ & $20(1 / 5)$ & $25(1 / 4)$ \\
\hline & \multirow[t]{2}{*}{$15^{\circ}$} & & $S$ & $100(\mathrm{I} / \mathrm{I})$ & $17(1 / 6)$ & $40(2 / 5)$ \\
\hline & & & I & $100(1 / I)$ & $0(0 / 0)$ & $0(0 / 3)$ \\
\hline & \multirow[t]{2}{*}{$21^{\circ}$} & \multirow[t]{2}{*}{$3^{\circ}$} & $S$ & $0(0 / 1)$ & $0(0 / 2)$ & $25(1 / 4)$ \\
\hline & & & I & $0(0 / 2)$ & $0(0 / 1)$ & $33(1 / 3)$ \\
\hline & \multicolumn{2}{|l|}{ Total } & & $30(12 / 40)$ & $35(29 / 84)$ & $26(22 / 84)$ \\
\hline \multirow[t]{16}{*}{ Nasal } & \multirow[t]{2}{*}{$1^{\circ}$} & \multirow[t]{2}{*}{$7^{\circ}$} & $S$ & $63(5 / 8)$ & 7I (5/7) & $88(7 / 8)$ \\
\hline & & & I & $33(1 / 3)$ & $57(4 / 7)$ & $29(2 / 7)$ \\
\hline & \multirow[t]{6}{*}{$3^{\circ}$} & \multirow[t]{2}{*}{$3^{\circ}$} & $S$ & $7 \mid(5 / 7)$ & $75(6 / 8)$ & $14(1 / 7)$ \\
\hline & & & I & $0(0 / 1)$ & $80(4 / 5)$ & $60(3 / 5)$ \\
\hline & & \multirow[t]{2}{*}{$15^{\circ}$} & $S$ & $33(1 / 3)$ & $29(2 / 7)$ & $44(4 / 9)$ \\
\hline & & & I & $0(0 / 1)$ & $33(2 / 6)$ & $40(2 / 5)$ \\
\hline & & \multirow[t]{2}{*}{$21^{\circ}$} & $S$ & $0(0 / 3)$ & $0(0 / 6)$ & $29(2 / 7)$ \\
\hline & & & I & $33(1 / 3)$ & $0(0 / 4)$ & $0(0 / 7)$ \\
\hline & \multirow[t]{2}{*}{$7^{\circ}$} & \multirow[t]{2}{*}{$5^{\circ}$} & $S$ & $22(2 / 9)$ & $40(4 / 10)$ & $50(4 / 8)$ \\
\hline & & & I & $0(0 / 6)$ & 7I (5/7) & $75(3 / 4)$ \\
\hline & \multirow[t]{2}{*}{$9^{\circ}$} & $9^{\circ}$ & $S$ & $0(0 / 3)$ & $25(2 / 8)$ & $75(6 / 8)$ \\
\hline & & & I & $50(2 / 4)$ & $17(1 / 6)$ & $60(3 / 5)$ \\
\hline & $15^{\circ}$ & $3^{\circ}$ & $\mathrm{S}$ & $0(0 / 5)$ & $31(4 / 13)$ & $63(5 / 8)$ \\
\hline & & & 1 & $0(0 / 3)$ & $43(3 / 7)$ & $67(4 / 6)$ \\
\hline & & $9^{\circ}$ & $S$ & $0(0 / 6)$ & $20(2 / 10)$ & $63(5 / 8)$ \\
\hline & & & I & $0(0 / 4)$ & $25(2 / 8)$ & $50(2 / 4)$ \\
\hline
\end{tabular}

(Continued) 
Table I (Continued).

\begin{tabular}{|c|c|c|c|c|c|}
\hline \multicolumn{2}{|l|}{ Test points } & \multirow{2}{*}{$\begin{array}{l}\text { Superior } \\
\text { /Inferior }\end{array}$} & Early & Moderate & Severe \\
\hline Horizontal & Vertical & & \multicolumn{3}{|c|}{ Detection rate of abnormal points (imo/HFA) } \\
\hline \multirow[t]{2}{*}{$21^{\circ}$} & \multirow[t]{4}{*}{$3^{\circ}$} & S & $13(1 / 8)$ & $31(4 / 13)$ & $38(3 / 8)$ \\
\hline & & I & $33(2 / 6)$ & $30(3 / 10)$ & $38(3 / 8)$ \\
\hline \multirow[t]{2}{*}{$27^{\circ}$} & & S & $17(1 / 6)$ & $31(4 / 13)$ & $38(3 / 8)$ \\
\hline & & I & $20(1 / 5)$ & $0(0 / 8)$ & $57(4 / 7)$ \\
\hline \multicolumn{2}{|l|}{ Total } & & $23(22 / 94)$ & $35(57 / 163)$ & $48(66 / 137)$ \\
\hline
\end{tabular}

\section{Disclosure}

The authors report no conflicts of interest in this work.

\section{References}

1. Maddess T, Bedford SM, Goh XL, James AC. Multifocal pupillographic visual field testing in glaucoma. Clin Exp Ophthalmol. 2009;37:678-686. doi: 10.1111/j.1442-9071.2009.02107.x

2. Carle CF, James AC, Kolic M, Essex RW, Maddess T. Blue multifocal pupillographic objective perimetry in glaucoma. Invest Ophthalmol Vis Sci. 2015;56:6394-6403. doi:10.1167/iovs.14-16029

3. Chibel R, Sher I, Ben Ner D, et al. Chromatic multifocal pupillometer for objective perimetry and diagnosis of patients with retinitis pigmentosa. Ophthalmology. 2016;123:1898-1911.

4. Asakawa K, Nanno M, Ishikawa H, Shoji N. Evaluation of pupil fields using a newly developed head-mounted perimeter in healthy subjects. J Glaucoma. 2018;27:807-815. doi:10.1097/IJG.0000000000001015

5. Asakawa K, Ishikawa H. Pupil fields in a patient with early-onset a postgeniculate lesion. Graefes Arch Clin Exp Ophthalmol. 2019;257:441-443. doi:10.1007/s00417-019-04345-8

6. Totsuka K, Asakawa K, Ishikawa H, Shoji N. Evaluation of pupil fields using a newly developed perimeter in glaucoma patients. Cur Eye Res. 2019;44:527-532. doi:10.1080/02713683.2018.1562078

7. Anderson DR, Patella VM. Automated Static Perimetry. 2nd ed. St Louis: Mosby; 1999:121-190.
8. Asakawa K, Shoji N, Ishikawa H, et al. New approach for the glaucoma detection with pupil perimetry. Clin Ophthalmol. 2010;21:617-623. doi:10.2147/OPTH.S9936

9. Yoshitomi T, Matsui T, Tanakadate A, Ishikawa S. Comparison of threshold visual perimetry and objective pupil perimetry in clinical patients. J Neuroophthalmol. 1999;19:89-99. doi:10.1097/00041327199906000-00003

10. Schmid R, Luedtke H, Wilhelm BJ, et al. Pupil campimetry in patients with visual field loss. Eur J Neurol. 2005;12:602-608. doi:10.1111/j.1468-1331.2005.01044.x

11. Hood DC, Anderson SC, Wall M, Kardon RH. Structure versus function in glaucoma: an application of a linear model. Invest Ophthalmol Vis Sci. 2007;48:3662-3668. doi:10.1167/iovs.06-1401

12. Tatsumi Y, Nakamura M, Fujioka M, et al. Quantification of retinal nerve fiber layer thickness reduction associated with a relative afferent pupillary defect in asymmetric glaucoma. $\mathrm{Br} J$ Ophthalmol. 2007;91:633-637. doi:10.1136/bjo.2006.105494

13. Adhikari P, Zele AJ, Thomas R, Feigl B. Quadrant field pupillometry detects melanopsin dysfunction in glaucoma suspects and early glaucoma. Sci Rep. 2016;6:33373. doi:10.1038/srep33373

14. Bizios D, Heijl A, Bengtsson B. Trained artificial neural network for glaucoma diagnosis using visual field data: a comparison with conventional algorithms. J Glaucoma. 2007;16:20-28. doi:10.1097/ IJG.0b013e31802b34e4
Clinical Ophthalmology

\section{Publish your work in this journal}

Clinical Ophthalmology is an international, peer-reviewed journal covering all subspecialties within ophthalmology. Key topics include: Optometry; Visual science; Pharmacology and drug therapy in eye diseases; Basic Sciences; Primary and Secondary eye care; Patient Safety and Quality of Care Improvements. This journal is indexed on PubMed
Central and CAS, and is the official journal of The Society of Clinical Ophthalmology (SCO). The manuscript management system is completely online and includes a very quick and fair peer-review system, which is all easy to use. Visit http://www.dovepress.com/ testimonials.php to read real quotes from published authors. 